\title{
Hydric Behavior of Earth Materials and the Effects of Their Stabilization with Cement or Lime: Study on Repair Mortars for Historical Rammed Earth Structures
}

\author{
Maria Idália Gomes, Ph.D. ${ }^{1}$; Teresa Diaz Gonçalves, Ph.D. ${ }^{2}$; and Paulina Faria, Ph.D. ${ }^{3}$
}

\begin{abstract}
Earthen building materials bear interesting environmental advantages and are the most appropriate to conserve historical earth constructions. To improve mechanical properties, these materials are often stabilized with cement or lime, but the impact of the stabilizers on the water transport properties, which are also critical, has been very rarely evaluated. The researchers have tested four earth-based repair mortars applied on three distinct and representative rammed earth surfaces. Three mortars are based on earth collected from rammed earth buildings in south of Portugal and the fourth mortar is based on a commercial clayish earth. The main objective of the work was over the commercial earth mortar, applied stabilized and not stabilized on the three rammed earth surfaces to repair, to assess the influence of the stabilizers. The other three earth mortars (not stabilized) were applied on each type of rammed earth, representing the repair only made with local materials. The four unstabilized earth materials depicted nonlinear dependence on $t^{1 / 2}$ during capillary suction. This behavior was probably caused by clay swelling. Stabilization with any of the four tested binders enabled the linear dependence of $t^{1 / 2}$ expected from Washburn's equation, probably because the swelling did not take place in this case. However, the stabilizers also significantly increased the capillary suction and the capillary porosity of the materials. This means that, in addition to increasing the carbon footprint, stabilizers, like cement and lime, have functional disadvantages that discourage their use in repair mortars for raw earth construction. DOI: 10.1061/(ASCE) MT.1943-5533.0001536. @ 2016 American Society of Civil Engineers.
\end{abstract}

Author keywords: Rammed earth; Repair mortar; Stabilization; Binder; Water transport.

\section{Introduction}

Building materials based on natural earth offer important environmental advantages, which is one of the main reasons for the interest they are raising around the world. Another important motivation is the need to conserve, using compatible materials, the earthen-built heritage, which includes many listed monuments and often whole historical centers. However, despite it being used in practice to build walls (rammed earth, adobe, or other techniques) or in mortars (plasters and renders, bedding, or repair mortar), the behavior of raw earth as a construction material is still poorly understood at a scientific level. In fact, the knowledge on this type of materials still derives mostly from soil science, which has different requirements. In building construction, this knowledge is still essentially practical, which hampers its own advancement and proper adaptation to new circumstances.

One of the most important characteristics of porous building materials is the way they transport and react to the presence of

${ }^{1}$ Assistant Professor, Dept. of Civil Engineering, Lisbon Engineering Superior Institute (ISEL), Rua Conselheiro Emídio Navarro 1, 1959-007 Lisboa, Portugal (corresponding author). E-mail: idaliagomes@dec.isel.pt

${ }^{2}$ Research Officer, Dept. of Materials, National Laboratory for Civil Engineering (LNEC), Av. do Brasil 101, 1700-066 Lisboa, Portugal. E-mail: teresag@lnec.pt

${ }^{3}$ Associate Professor, Dept. of Civil Engineering, Civil Engineering Research and Innovation for Sustainability (CERIS), ICIST, Nova Univ. of Lisbon (UNL), Campus da Caparica, 2829-516 Caparica, Portugal. E-mail: paulina.faria@fct.unl.pt

Note. This manuscript was submitted on April 23, 2015; approved on November 16, 2015 No Epub Date. Discussion period open until 0, 0; separate discussions must be submitted for individual papers. This paper is part of the Journal of Materials in Civil Engineering, (C) ASCE, ISSN 0899-1561. moisture, i.e., their hydric behavior. As evidenced by practice, this is particularly significant for earth-based materials in which the binder is clay. Clays are composed by stacked sheets of silica and alumina linked by van der Waals and hydrogen bonds. They may undergo significant swelling in the presence of water, especially those with weaker (hydrogen) bonds, which are also usually the best binders. However, despite this sensitivity, the hydric performance of earth-based materials has been very sparsely addressed in scientific literature.

Earth-based materials are often stabilized with small amounts of lime or cement with the aim of improving their mechanical resistance and durability (Heathcote 1995; Jayasinghe and Kamaladasa 2007; Jaquin et al. 2008; Hall and Allinson 2009; Hossain and Mol 2011). Indeed, many standards and other regulatory documents on earth construction recommend cement or lime stabilization (Ashurst and Ashurst 1995; SAZS 2001; New Mexico Code 2006; Jiménez Delgado and Guerrero 2007). However, that eventual improvement is still not totally proven, and little is known about the influence these stabilizers may have on the hydric properties of the material, which, as explained, is also critical (Cid et al. 2011; Gomes et al. 2012a). Furthermore, the uses of chemical stabilizers, like these types of binders, contribute to the increase of mortar's embodied energy because of the energy needed to produce the binders in comparison with the clayish earth preparation. Also, it completely changes the life cycle of the earth material itself, namely in terms of its possibilities for reuse. In one of the few studies about the influence that stabilizers may have on the hydric properties of earth building materials, Hall and Allinson (2009) report a significant increase in the porosity and sorptivity of rammed earth specimens when they were stabilized with portland cement (CEM II). This suggests that stabilizers may significantly affect the hydric properties of earth materials, which requires further attention. Does 

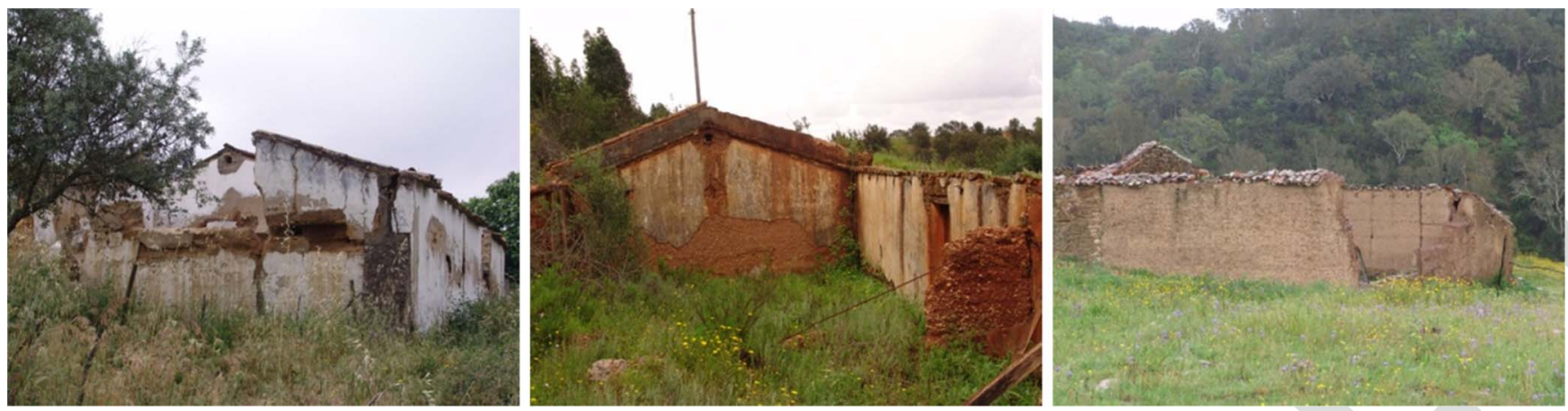

Fig. 1. Earth buildings from which Av, PD and VC earths were collected (images by M. I. Gomes)

the observed effect depend on the content of cement? Will it happen for other types of mineral binders?

The researchers addressed these two questions in an experimental study about the hydric behavior of earth-based repair mortars for rammed earth walls, which are presented in this paper. This work was based on capillary absorption tests performed on small specimens and rammed earth blocks made from four different types of earth. One is a commercial earth, which was subjected to stabilization with 5,10 , or $15 \%$ of each of the following binders: dry hydrated air lime (CL), natural hydraulic lime (HL), and portland cement (PC) or natural cement (NC). The other three types of earth were collected from the walls of old rammed earth buildings in southern Portugal. These buildings are part of a valuable heritage, historic testimony of sustainable construction techniques based on the use of local materials. Despite the interest, most are abandoned or require deep conservation interventions or even partial reconstruction, which shows how urgent it is to acquire sufficient knowledge about suitable repair materials in order to enable and encourage their conservation and transmission to future generations.

\section{Materials and Specimens}

One of the four earths used in the experiments is a clayey commercial earth, here named reference earth (RE). The other three (Avis-Av, Pá Danado-PD, and Val Chaim-VC) were collected from nondamaged parts of walls of unstabilized rammed earth buildings located in Alentejo region in southern Portugal (Fig. 1). They are local earths; Av and VC are silty sandy soils, whereas PD is a clayey sand soil (Table 1). The four materials are fully characterized elsewhere (Gomes et al. 2012a, 2014).

The samples Av, PD, VC, and RE were previously grinded and sieved through a sieve of 106 microns (sieve n. ${ }^{\circ} 140$ ASTM) and then analyzed by X-ray diffraction (XRD), using a Philips X'Pert diffractometer with $\mathrm{Fe}$-filtered cobalt $K \alpha$ radiation, operating at $35 \mathrm{kV}$ and $45 \mathrm{~mA}$. Powder diffraction data were collected in the range $3-74^{\circ}(2 \theta)$ in steps of $0.05^{\circ} / \mathrm{s}(2 \theta / \mathrm{s})$. To identify the mineral phases, a HighScore X'Pert software was used and by comparison identified with the International Centre for Diffraction Data Powder Diffraction Files, which compares the experimental peaks with the ICDS database. The results are shown in Fig. 2. Quartz, mica, and feldspars were detected in all the samples. Mica may correspond to different types of clay minerals, all of which, however, present small volumetric changes in the presence of water. The clay minerals present in larger amounts are chlorite in Av and VC and kaolinite in all samples. These types of clay also show small volumetric changes in the presence of water.

\section{Manufacture of the Rammed Earth Blocks}

It would not have been possible to use blocks cut directly from the rammed earth walls because (1) the extraction of such blocks is not physically possible because of their poor mechanical strength; and (2) rammed earth blocks cut from the same building would not be identical, and therefore, tests in controlled conditions would not be possible. For that reason, rammed earth blocks were manufactured, with each of the three types of earth collected from rammed earth constructions (Av, PD, and VC). The material collected was firstly disaggregated with a rubber hammer (not to break the aggregates) and then dry sieved, rejecting the material retained in the $12.5-\mathrm{mm}$ sieve (\#1/2 in. ASTM), Fig. 3(a). After that, ten rammed earth blocks of each of the collected earths, with dimensions $30 \times 20 \times 28 \mathrm{~cm}$, were manually prepared with the help of plywood boxes [Fig. 3(b)]. A total of thirty blocks were manufactured.

Immediately after completing a block, the plywood was removed, and one type of standard defect was recreated on the larger surface of the block. This was a superficial defect and was performed by scraping with a spatula until a cavity with 2 to $2.5 \mathrm{~cm}$ depth and an area of $25 \times 22\left(\mathrm{~cm}^{2}\right)$ was formed, as seen in Fig. 3(c). This defect is commonly found on the exterior surfaces of rammed earth walls and represents superficial erosion (Gomes and Faria

Table 1. Grain Size Fractions, Maximum Particle Size, and Soils Classification of the Earths Used

\begin{tabular}{lcccc}
\hline Earth & Local earth Av & Local earth PD & Local earth VC & Reference-earth RE \\
\hline Clay (\%) <0.002 mm & 9.0 & 26.5 & 17.5 & 31.0 \\
Silte (\%) 0.002-0.06 mm & 13.5 & 21.1 & 17.7 & 20.0 \\
Sand (\%) 0.06-2 mm & 68.7 & 22.5 & 32.8 & - \\
Gravel (\%) 2-60 mm & 8.8 & 29.9 & - & 1.0 \\
Pebble (\%) 60-150 mm & - & 50.80 (Sieve 2 in.) & 101.6 (Sieve 4 in.) \\
Maximum size of the particles (mm) & 19.05 (Sieve 3/4 in.) & Clayey sand & Silty sand (Sieve \#10) \\
Soils classification & Silty sand & & Clayey \\
\hline
\end{tabular}




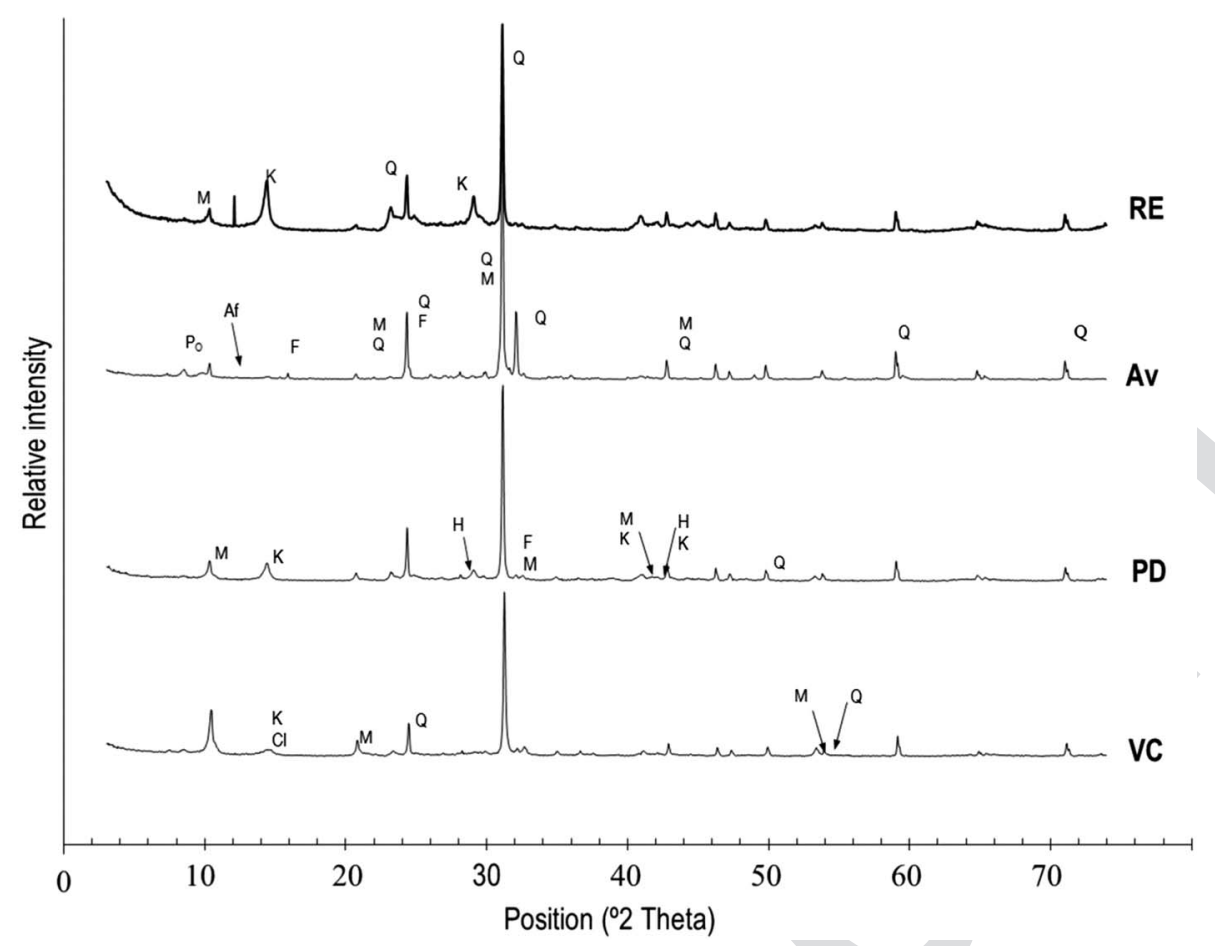

Fig. 2. X-ray diffractograms of the four earth materials used. The peaks correspond to each identified crystalline phase: Q- quartz, F-feldspar, $\mathrm{M}$-mica, $\mathrm{Cl}$ - chlorite, $\mathrm{K}$-kaolinite, $\mathrm{H}$ - hematite, and $\mathrm{Po}$ - sample holder

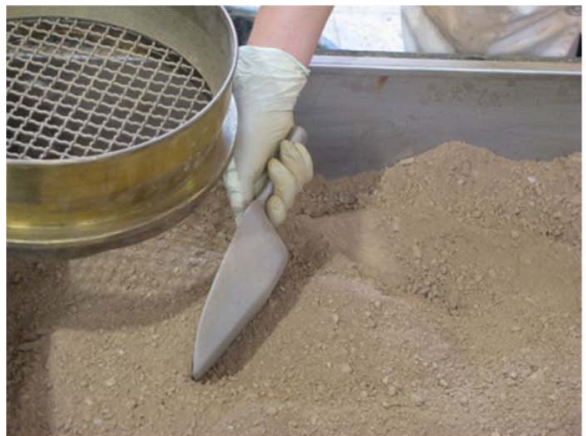

(a)

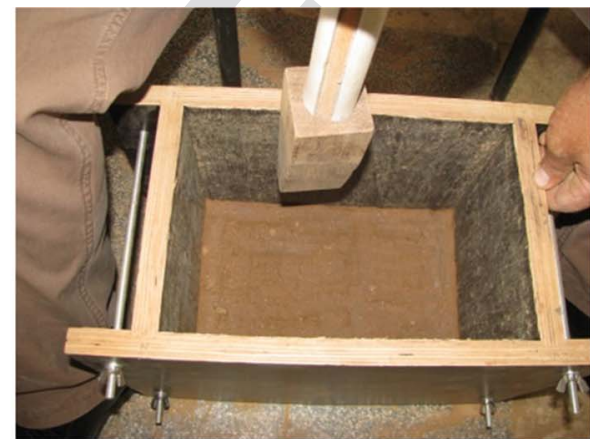

(b)

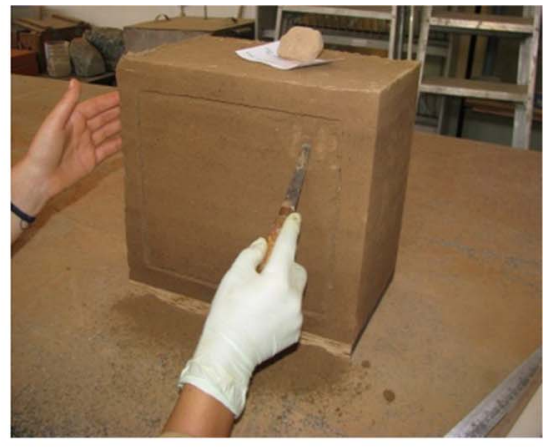

(c)

F3:1 Fig. 3. (a) Preparation of the material; (b) manufacture of a rammed earth block; (c) recreating a superficial defect on a rammed earth block

2011). More details on the preparation of the earth materials and manufacture of the blocks can be found in Gomes et al. (2012b).

\section{Mortars Production}

The stabilized and unstabilized earths were used to produce mortars (Mortar Avis-MAv, Mortar Pá Danado-MPD, Mortar Val Chaim-MVC, and Mortar Reference Earth-MRE) to test as small mortar specimens and to apply on the unstabilized rammed earth blocks.

MAv, MPD, and MVC correspond to the alternative of repairing rammed earth walls with local earths - the same previously used to build the walls. Because of that, no stabilizer was added. The MRE mortars correspond to the alternative repair of different rammed earth walls using a different material from the one used to build the walls. For that reason, their behavior will be analyzed with and without the addition of stabilizers. Thereby, mortar with the four earths were tested in their nonstabilized state, whereas the (commercial) earth RE was also tested after stabilization with each one of the following binders, used in three alternative proportions $(5,10$ or $15 \%$, relative to the mass of earth):

- CL-dry hydrated air lime CL90-S, EN 459-1 (CEN 2012);

- HL-natural hydraulic lime HL5, EN 459-1 (CEN 2012);

- PC-portland cement CEM II/BL 32.5N, EN 197-1 (CEN 2011); and

- NC-natural cement, [ROCARE EU-Project (2012)].

The three types of earth collected in situ (Av, PD, and VC) were previously wet sieved. Only the material that passed through the 2-mm sieve ( ${ }^{\circ} .10$ ASTM) was used in this work. This material was decanted, dried in a ventilated oven at $40^{\circ} \mathrm{C}$, and finally ground and homogenized. Sieving was not carried out on the reference earth. Because of its large amount of clay, it was only necessary to ground, disaggregate, and then homogenize it.

With the objective of reducing shrinkage, which otherwise would be very high, PD, VC, and RE earths were physically 
Table 2. Loose Bulk Density of Each Type of Earth and Volumetric and Weight Proportion of Repair Mortars

\begin{tabular}{llcccc} 
T2:1 & Types of earth & $\begin{array}{c}\text { of the } \\
\text { mortar }\end{array}$ & $\begin{array}{c}\text { bulk density } \\
\left(\mathrm{kg} / \mathrm{m}^{3}\right)\end{array}$ & $\begin{array}{c}\text { proportion } \\
\text { (earth:sand) }\end{array}$ & $\begin{array}{c}\text { proportion } \\
\text { (earth:sand) }\end{array}$ \\
\cline { 2 - 6 } T2:2 & Local earth Av & MAv & 1,461 & $1: 0$ & $1: 0$ \\
T2:3 & Local earth PD & MPD & 1,105 & $1: 1.5$ & $1: 1.9$ \\
T2:4 & Local earth VC & MVC & 1,002 & & $1: 2.4$ \\
T2:5 & Reference-earth RE & MRE & 1,136 & $1: 3$ & $1: 3.8$ \\
\hline
\end{tabular}

stabilized through the addition of a siliceous sand (mainly composed of quartz, with dimensions in the range of 0.6 to $2.0 \mathrm{~mm}$ ).

The final composition and particle size distribution of the earth mortars are shown in Table 2 and Fig. 4.

The mixing of these mortars was carried out following EN 196-1 as closely as possible (CEN 2005). A mechanical mixer driven by an electric motor was used. For mortars MAv, MPD, and MVC, mixing was preceded by manual homogenization of the dry material. Then, water was introduced in the mixer, followed by the dry material. The mixture was made at low speed during $90 \mathrm{~s}$. After that, the mixing was stopped for another $90 \mathrm{~s}$ and, at the end, another mixing was made at slow speed for further $60 \mathrm{~s}$.

For the MRE mortar, the mixing time had to be increased to achieve a good homogenization because of the large clay content. Thus, after the introduction of water in the vat, a manual mixing for 2 min was done. This step was necessary to assure a uniform wetting of the mixture because otherwise, even in low speed, the mixture would splash; also, the first mixture was extended for $150 \mathrm{~s}$ in order to make the mixture more homogeneous.

The amount of water to use in the mortars was determined based on the consistence by flow table results [EN 1015-3 (CEN 1999b)]. This amount was necessary to achieve a flow between 160 and $176 \mathrm{~mm}$, which corresponds to the earth-based mortars with excellent workability (Gomes et al. 2012b). Details can be seen in Gomes et al. (2012a) and Gomes et al. (2013).

EN 1015-11 (CEN 1999a) was followed to produce the mortar specimen, albeit with some adjustments because this standard is not specific for earth mortars. The specimens were kept in a conditioned room $\left(20 \pm 2^{\circ} \mathrm{C}\right.$ and $\left.50 \pm 5 \% \mathrm{RH}\right)$ in molds for 7 days, in a sealed polyethylene bag. The specimens remained in the molds for 7 additional days without the bag; after that, they were demolded and remained in the same conditioned room until they reached the age of 90 days. The mortars with dry hydrated air-lime (CL) were placed in a carbonation chamber $\left(5 \% \mathrm{CO}_{2}, 21 \pm 2^{\circ} \mathrm{C}\right.$ and $71 \pm 2 \% \mathrm{RH})$ for 7 days to ensure complete carbonation.
Applying the Mortars on the Rammed Earth Blocks

The blocks were kept in a controlled environment at $20^{\circ} \mathrm{C}$ and $50 \%$ relative humidity $(\mathrm{RH})$ for 20 months. Afterwards, the standard defects were repaired with the unstabilized and stabilized earth mortars. The three mortars made from local earths, MAv, MPD, and MVC, were only used in the blocks composed of the same type of earth. Differently, the mortars made from commercial earth MRE, which are intended for more general use, were applied on all types of blocks, i.e., on all the three types of rammed earth.

Before applying the repairing mortars, the rammed earth surfaces were brushed to remove loose particles and wetted to avoid a sudden drying of the mortar, thereby to prevent a large initial retraction. After that, the mortar was firstly thrown vigorously against the support with a trowel, always from the bottom to top. Afterwards, it was tightened, and repointing of lacunae, particularly at the corners, was carried out. Finally, the surface of the mortar was regularized with a wooden trowel and smoothed with a sponge (Fig. 5). For each mortar, three applications on blocks were always carried out. The application technique of the repair mortars on the blocks is detailed in Gomes et al. (2013).

\section{Testing}

\section{Tests on Small Mortar Specimens}

The experimental work included tests on small mortar specimens to evaluate the drying shrinkage and the capillary water absorption of the hardened mortars (mortar specimens conditioned in the room at $20 \pm 2^{\circ} \mathrm{C}$ and $50 \pm 5 \% \mathrm{RH}$ for 90 days).

The shrinkage of the earth mortars was evaluated using a modified version of Alcock's test, which allows measuring not only the linear shrinkage but also the volumetric shrinkage (Gomes et al. 2014). The test approximately followed the procedure proposed by Keable (1996). Boxes made of film-faced plywood with internal dimensions of $300 \times 30 \mathrm{~mm}$ and an internal height of $30 \mathrm{~mm}$ $\left(270 \mathrm{~cm}^{3}\right)$ were used.

The capillary water absorption tests were carried according to the Réunion Internationale des Laboratoires et Experts des Matériaux (RILEM) procedure (RILEM 1980) and EN 15801 (CEN 2009) using six cubic specimens $(50 \times 50 \times 50 \mathrm{~mm})$ of each type of earth mortar. The result of this test is given as a curve, the capillary absorption curve, that expresses the amount of water absorbed per unit area $\left(\mathrm{kg} \cdot \mathrm{m}^{-2}\right)$ as a function of the square root of the elapsed time $\left(\mathrm{s}^{1 / 2}\right)$. The slope of the linear portion of this

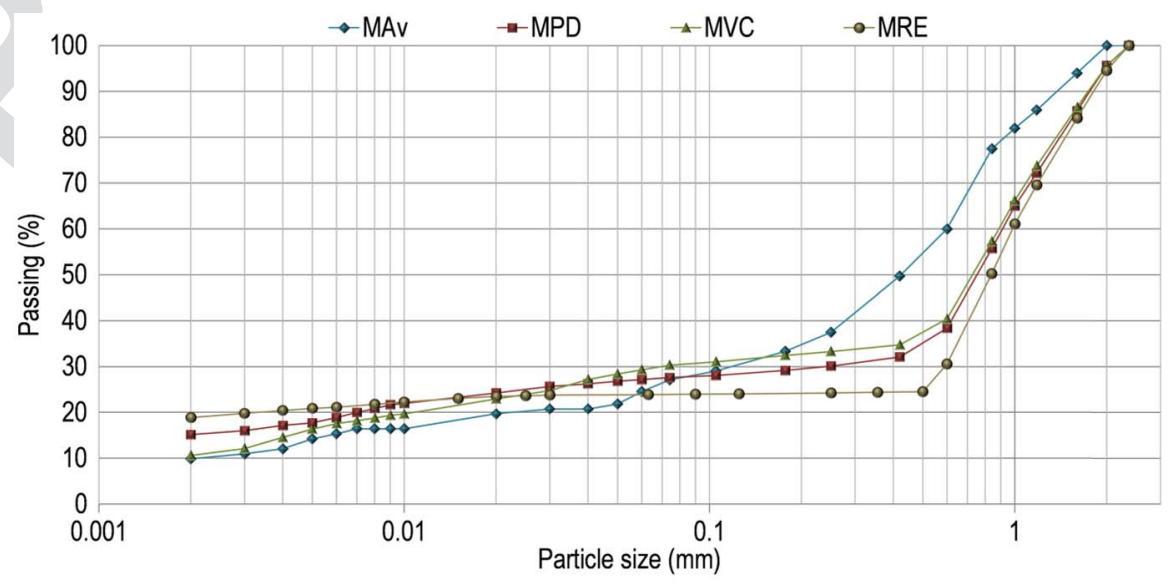

Fig. 4. Dry particle size distribution of the mortar materials, MAv, MPD, MVC, and MRE 

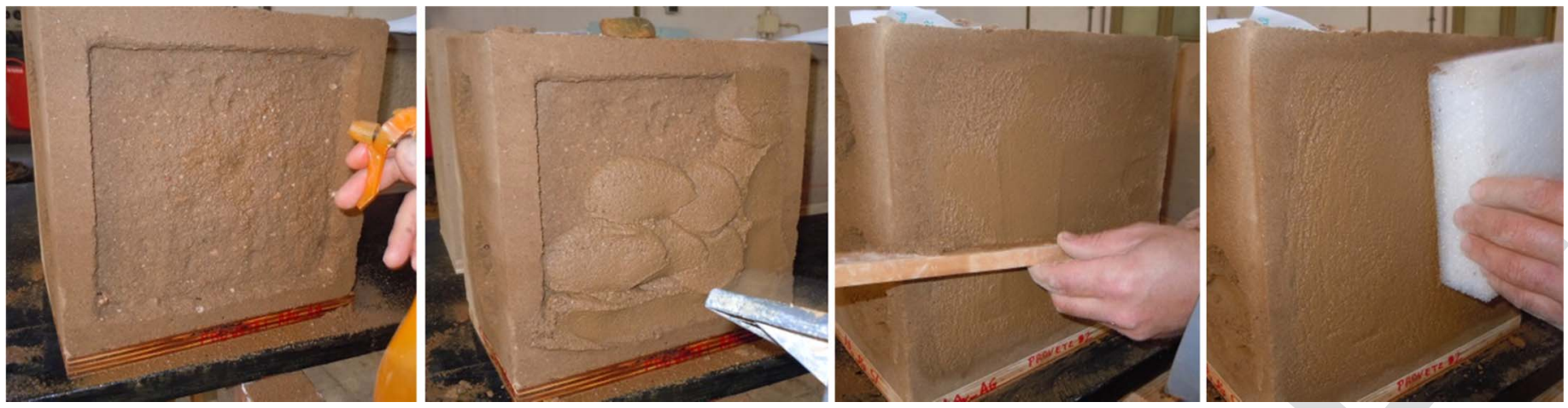

Fig. 5. Application sequence of the earth repair mortar on the superficial defect

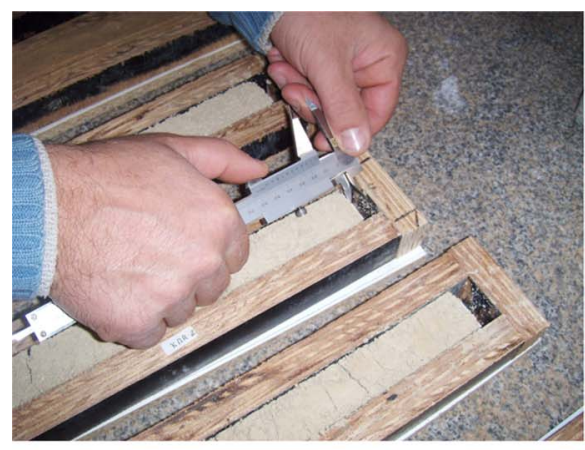

(a)

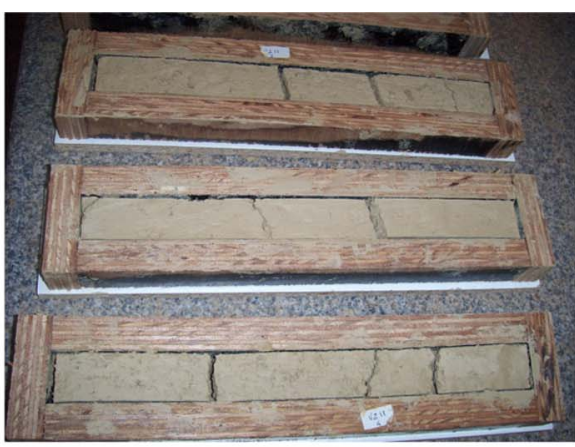

(b)

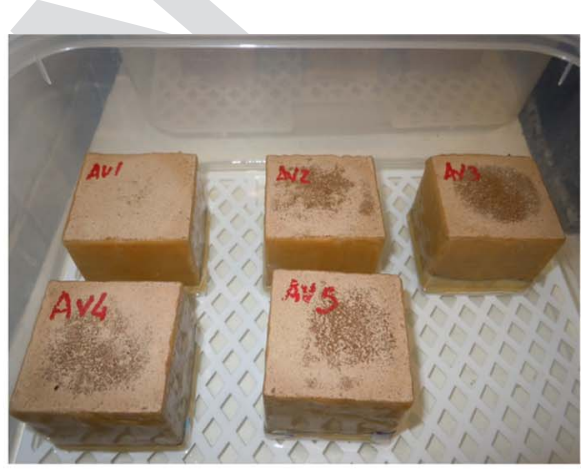

(c)

Fig. 6. (a) Alcock's test, measurement of the linear shrinkage; (b) Alcock's test showing the volumetric shrinkage; (c) capillary water absorption test

curve corresponds to the capillary water absorption coefficient (WAC). Fig. 6 shows the Alcock's test and the capillary water absorption test.

The amount of absorbed water by a porous solid, $\mathrm{W}\left(\mathrm{kg} \cdot \mathrm{m}^{-2}\right)$, after the period of immersion $\mathrm{t}(\mathrm{s})$ per unit of surface area is proportional to the square root of time [Eq. (1)]. The slope of this linear function of $t^{1 / 2}$ is $\mathrm{A}\left(\mathrm{kg} \cdot \mathrm{m}^{-2} \cdot \mathrm{s}^{-1 / 2}\right)$, the so-called water absorption coefficient, which is derived from Washburn's equation [Eq. (2)]

$$
W(t)=A \cdot \sqrt{t}
$$

The displacement $d$ of the water in a capillary is given, as a function of time $t$, by Eq. (2), which is derived from Poiseuille's experimental law (Washburn 1921). This equation describes the horizontal movement of water in a capillary but can also be applied to vertical movement if gravity effects were neglected. It shows that water travels more quickly through large capillary pores, which hence are filled firstly during soaking

$$
d(t)=\left(\sqrt{\frac{\sigma \cdot r \cdot \cos \varphi}{2 \eta} \cdot t}\right)
$$

where $d(\mathrm{~m})=$ distance that the meniscus travels in the capillary during time $t(s) ; \eta\left(\mathrm{kg} \cdot \mathrm{m}^{-1} \cdot \mathrm{s}^{-1}\right)=$ dynamic viscosity of water; $\sigma(\mathrm{N} / \mathrm{m})=$ surface tension of water; $r(\mathrm{~m})=$ capillary radius; and $\phi=$ contact angle.

\section{Tests on Rammed Earth Blocks Repaired with the Earth Mortars}

The rammed earth blocks with the repair mortars were subjected to capillary absorption, which was held approximately 120 days after the application of the mortars in the respective blocks. In order to compel that, drying was mainly made through the mortar layers (applied on the vertical faces of the blocks); the upper face of the blocks were waterproofed using a mixture with a mass proportion of $50 \%$ pitch blond and $50 \%$ beeswax. The blocks were subjected to partial absorption, leaving the free water surface approximately 1 to $2 \mathrm{~cm}$ above the base of the blocks for $120 \mathrm{~h}$. The water absorption on the blocks was mainly performed from the lateral sides (1-2 cm water high) and not from its base because the blocks were constructed on plywood boards for easy transport, restricting the deterioration. This setup simulates the common case in which water slashes or accumulates near the base of the wall. Indeed, well-constructed earth walls are not directly built from the ground, and therefore, capillary uptake from the base of the blocks would not be a realistic situation.

After $24 \mathrm{~h}$ in partial immersion, in some cases, the water absorption by capillarity seems to be very low, and the area near the base of the blocks was already very damaged. Because of the degradation on the base of the blocks, an environment with high relative humidity was generated in order to limit the evaporation of water, creating conditions for a faster rising damp. Thus, all the blocks were covered with a polyethylene film, remaining in partial immersion to complete the $120 \mathrm{~h}$.

\section{Results and Discussion}

\section{Tests on Small Mortar Specimens}

The capillary absorption curves obtained on the test with small mortar specimens, whose method is described in the section titled "Tests on Small Mortar Specimens" in the "Testing" section of the 


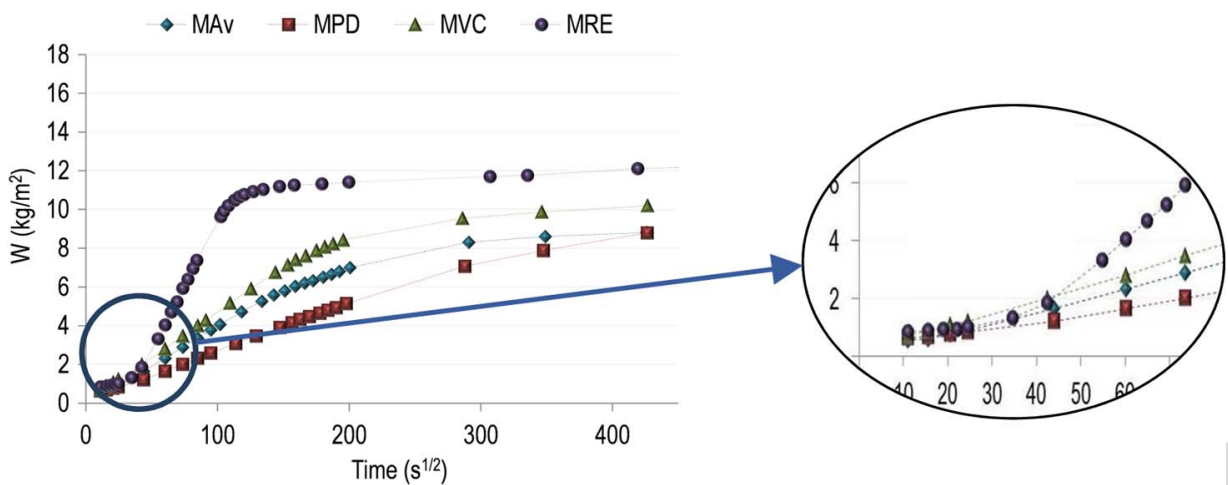

Fig. 7. Absorption curves showing in detail the first minutes of capillary suction of the unstabilized mortars

F8:1 F8:2 paper, are shown in Figs. 7 and 8. The unstabilized MRE mortar is repeated in the four plots to serve as a reference. It is found that the inflection point between the two segments in the absorption curve, the moment that the capillary fringe reaches the surface in the specimen, occurs firstly in stabilized mortars.

When a porous material is in free contact with water, it soaks liquid up to a certain critical moisture content, the so-called capillary saturation moisture content. Total saturation, which corresponds to total filling of the open porosity, cannot usually be reached under normal suction conditions within a reasonable period of time because a certain volume of air is generally trapped in the pore network, as well as because capillary suction by the macropores may be insignificant (Gonçalves 2007).

In practical experiments, such as the RILEM test (RILEM 1980) followed in the authors' work, the initial (steady-state) linear segment of the absorption curve is followed by a curved branch that slowly converges to horizontal. This curved branch starts when the wet fringe first reaches the opposite extreme of the specimens, therefore, marking the end of the steady-state period of capillary absorption.

This is the behavior that generally occurs and is theoretically expected in homogeneous porous materials. In this work, this type 


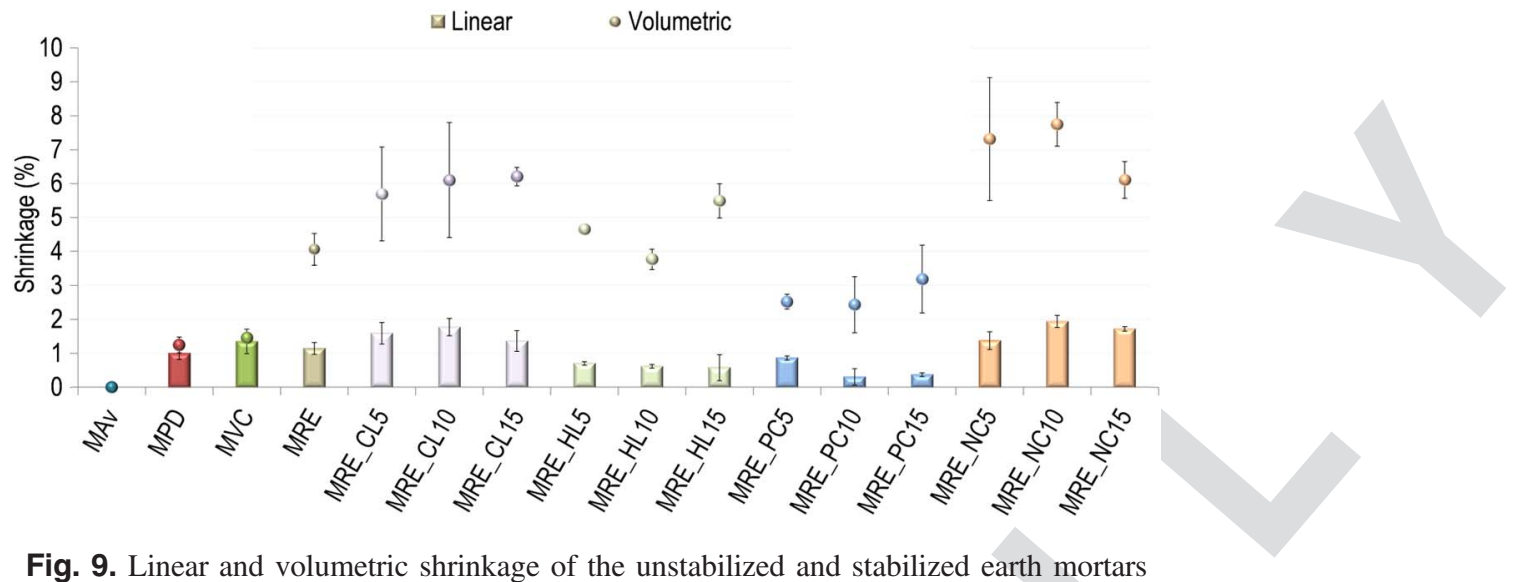

of behavior was observed for all the stabilized earth mortars, as seen in Fig. 8. Strikingly, however, it did not occur for the unstabilized mortars, which depicted nonlinear (exponential) dependence on $t^{1 / 2}$ during the first minutes, rather than the expected linear dependence on $t^{1 / 2}$. After approximately $3 \mathrm{~h}$ of testing (100 seg $\left.{ }^{1 / 2}\right)$ and comparing the four nonstabilized mortars (Fig. 7), a clear difference can be noticed for the MRE mortar; in fact, this mortar displays twice the value of absorbed water (W) in the absorption curve when compared with the others.

The researchers hypothesize that the anomaly observed in the unstabilized mortars is caused by the occurrence of clay swelling, which reduces the pore size, thereby increasing the quantity of capillary active pores. Swelling should start at the first contact of the clay with water and then decrease progressively until maximum expansion is attained, which corresponds to the moment in which the curve becomes linear.

The use of stabilizers eliminates swelling, thereby enabling the perfect $t^{1 / 2}$ linear dependence observed for the stabilized materials.

This hypothesis is consistent with the fact that the anomalous behavior is particularly relevant for the MRE mortar, which, as seen in Fig. 9, is also the one with the higher drying volumetric shrinkage $(4.1 \%$ volumetric shrinkage in the Alcock's tests, against 0.0 , 1.2 , and $1.5 \%$ for the MAv, MPD, and MVC mortars, respectively). This anomalous suction behavior disappears with the addition of even the smallest amounts of binder.
Despite this regularization effect, the stabilizers did not improve the hydric performance of the earth mortars. Indeed, Fig. 10, where the WAC of the unstabilized mortars was calculated disregarding the initial suction anomaly, depicts the WAC and the amount of water contained in the specimens at capillary saturation $\left(W_{\max }\right)$, showing that (1) the stabilizers can significantly increase the capillary suction; and (2) they can also increase the maximum amount of water absorbed, i.e., the capillary porosity of the material.

These effects are more relevant for the stabilization with dry hydrated air lime (CL) and, above all, portland cement (PC). However, they are also clear for the higher contents of natural hydraulic lime (HL) and natural cement (NC).

Comparing the values of the WAC at $10 \mathrm{~min}$ of the unstabilized earth mortar (MRE) with stabilized earth mortars using HL and PC (Fig. 11), it is possible to see that WAC at 10 min increases with the percentage of binder in both cases. The maximum value is shown for earth mortar stabilized with portland cement MRE_PC15 with $5.1 \mathrm{~kg} /\left(\mathrm{m}^{2} \cdot \mathrm{min}^{1 / 2}\right)$.

The initial rate of suction (IRS), $\mathrm{kg} /\left(\mathrm{m}^{2} \cdot \mathrm{min}\right)$, is given as the quantity of water absorbed per unit inflow surface area against elapsed time. As seen in Fig. 12, the initial rate of suction is also higher with increased concentration of the binder.

Studies on cement-based materials have also revealed deviations from the expected linear dependence of the absorption curve on $t^{1 / 2}$ (Hall et al. 1995; Lockington and Parlange 2003), but that is much

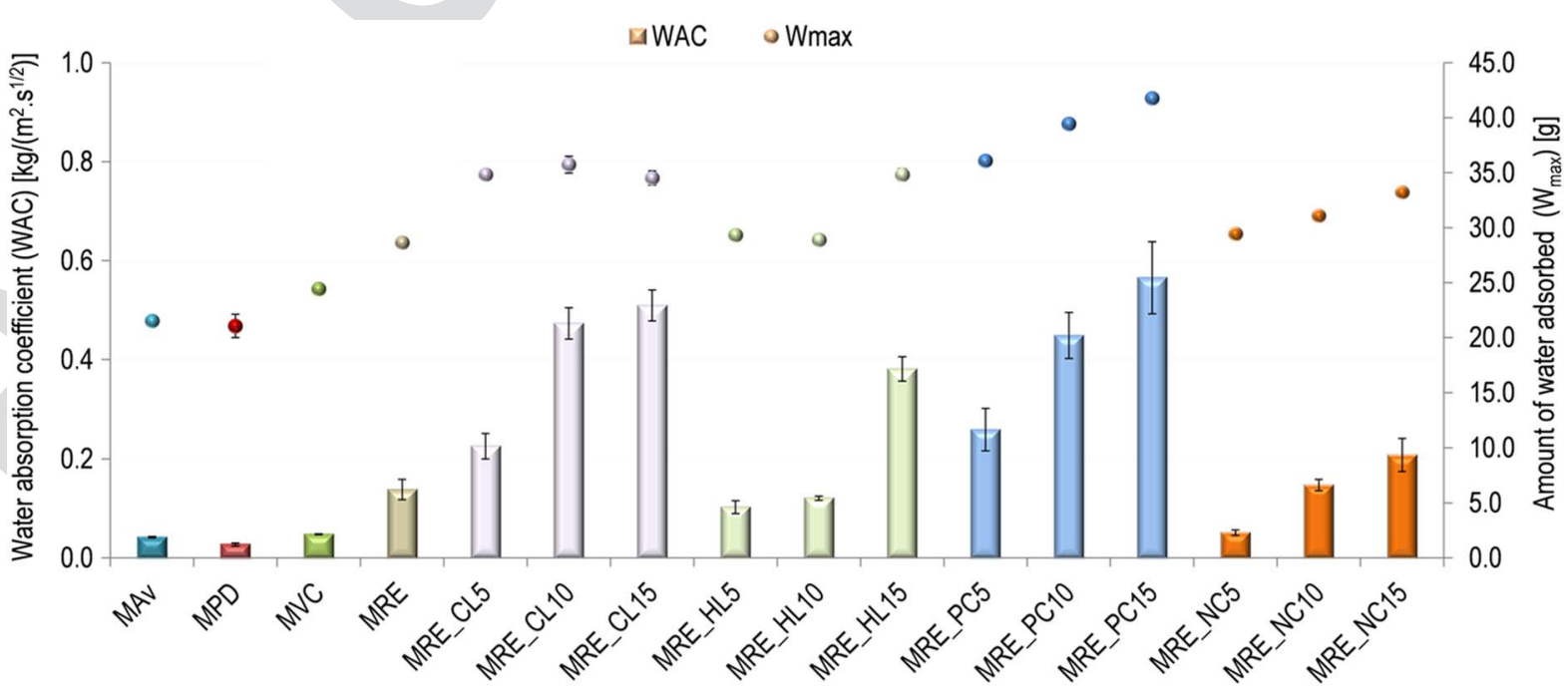

Fig. 10. Water absorption coefficient (WAC) and amount of water contained at capillary saturation (Wmax) of the tested mortars 

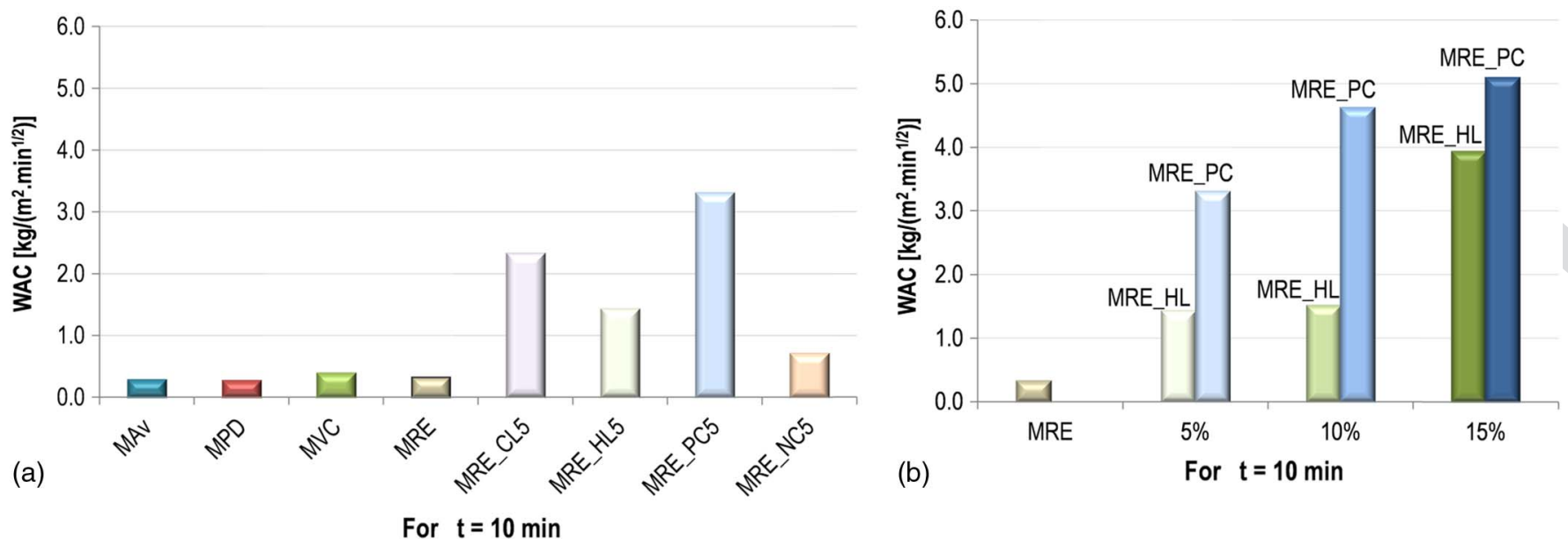

(b)

For $\mathrm{t}=10 \mathrm{~min}$

F11:1

Fig. 11. Water absorption coefficient (WAC) of the tested mortars after 10 min: (a) for unstabilized mortars and stabilized with 5\% of CL, NHL, PC, and NC; (b) for the MRE mortars with different concentration of HL or PC
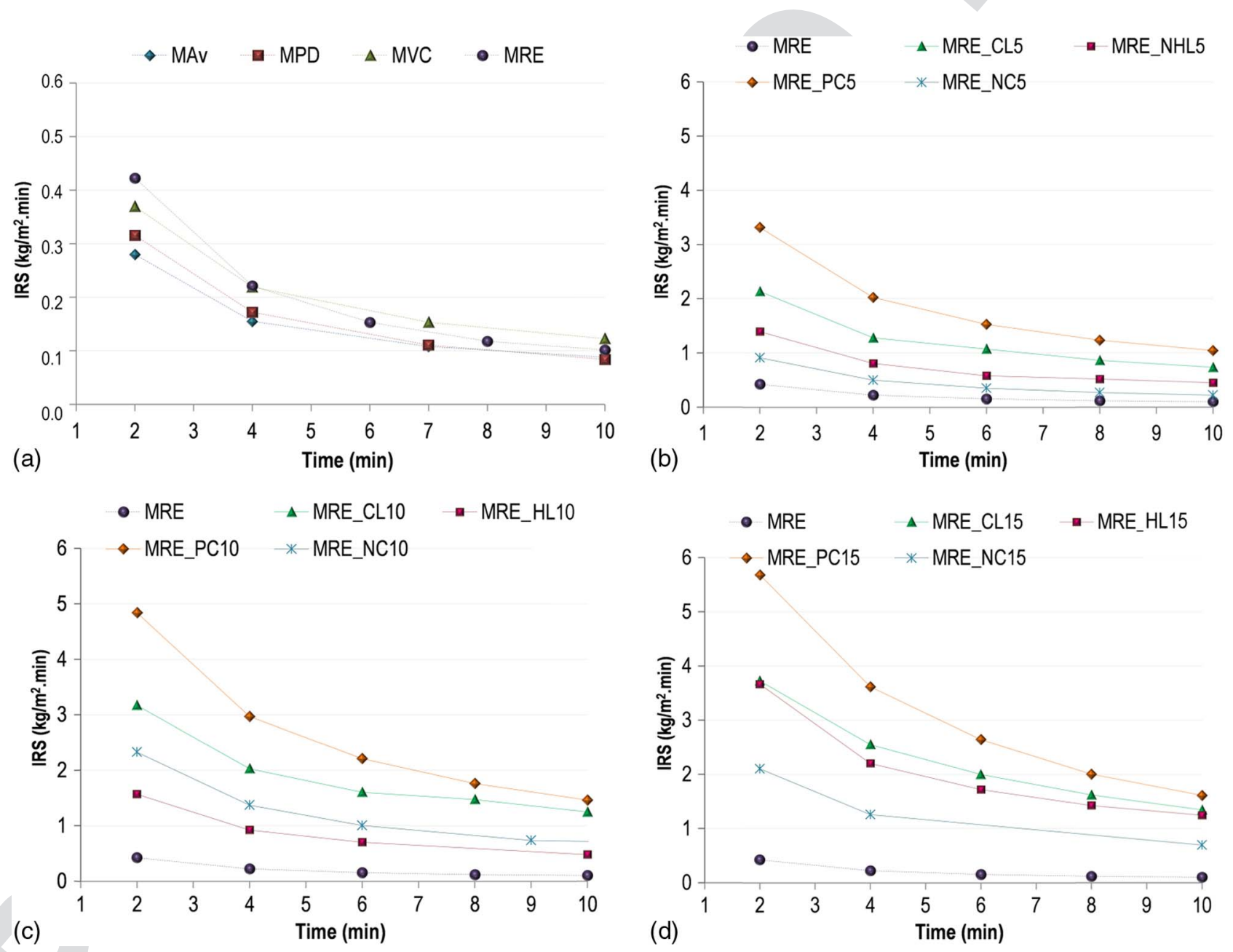

Fig. 12. Influence of the different binders on the initial rate of suction (IRS):

Time (min)

rarer for earth materials. Indeed, to the best of our knowledge, Hall and Allinson (2009) are the only ones who have already reported this type of phenomena for earth materials. They showed that cement stabilization could enable linear dependence on $t^{1 / 2}$ and also that the rate of suction of the earth materials increased with the cement content. In their work, the IRS was considerably higher with increased cement content. The subsequent decrease in suction over elapsed time was also more rapid. Our results confirm and extend their conclusions, showing that other hydraulic binders and also air lime can also significantly increase the capillary 


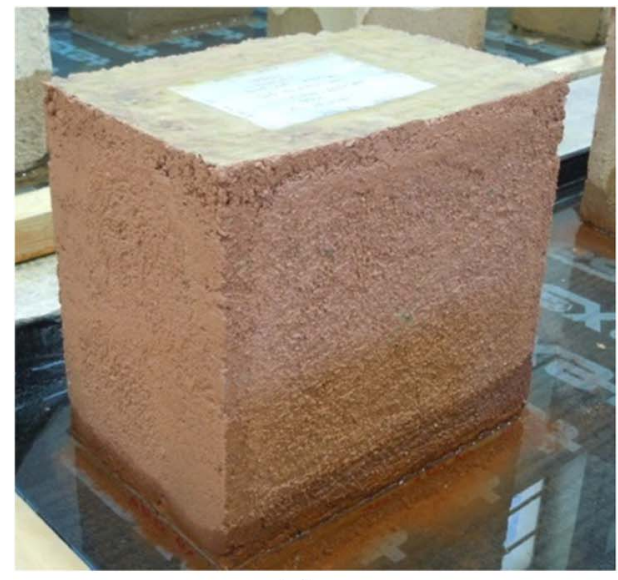

(a)

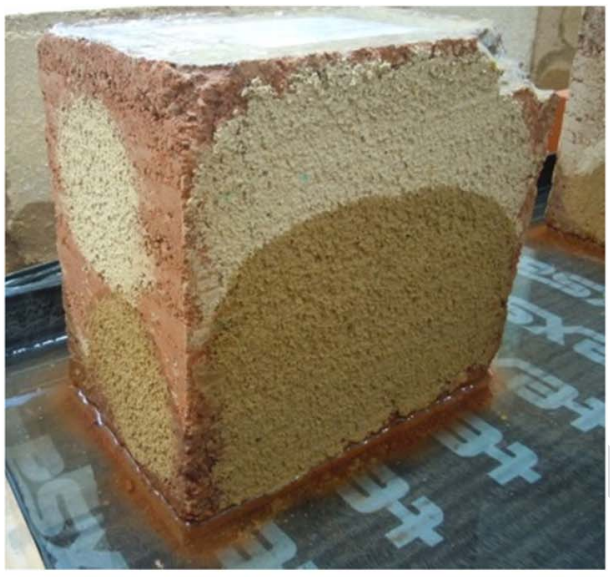

(b)
F13:1

Fig. 13. Capillary absorption test performed on rammed earth blocks with PD material after $12 \mathrm{~h}$ : (a) unstabilized mortar with the same material of the block, MPD; (b) mortar with reference earth and portland cement, MRE_PC

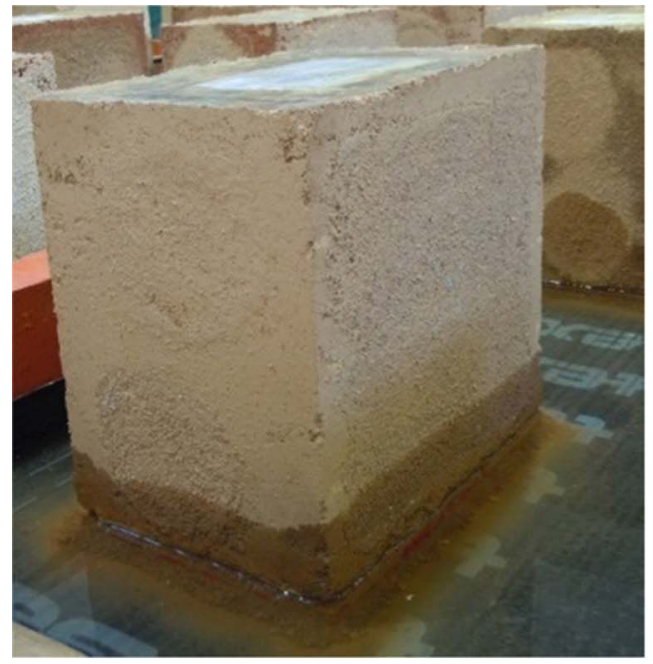

(a)

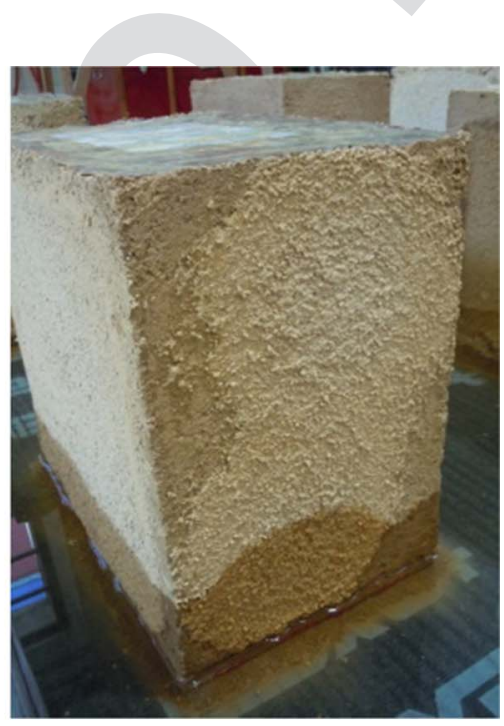

(b)
F14:1

Fig. 14. Capillary absorption test performed on rammed earth blocks with VC material after $12 \mathrm{~h}$ : (a) unstabilized mortar with the same material of the block, MVC; (b) mortar with reference earth and natural hydraulic lime, MRE_HL

porosity of the earth material. The results of Arizzi et al. (2012), showing that the water uptake in mortars (binder/sand mortars, with no clay) increased with the content of binder, also support this idea.

\section{Tests on Rammed Earth Blocks}

The results of the capillary absorption test that were carried out on rammed earth blocks repaired with (stabilized or unstabilized) earth mortars agree with the results of the tests on small specimens that have been discussed. It was observed that in the cases in which the repair had been made with a stabilized mortar (MRE with mineral binder), the capillary fringe progressed more quickly through the mortar than through the rammed earth of the block (Figs. 13 and 14). This would lead to higher heights of capillary rise in constructions. However, that did not happen for the unstabilized mortars (MAv, MPD, MVC, and MRE) through which the capillary fringe progressed more slowly, both in the block and the mortar, for the same testing time.
Comparing the capillary absorption of the different types of unstabilized mortar (Figs. 13-15), it is possible to conclude that sandy earths (Av material) have a much faster capillary absorption than clayey earths (PD, VC, and MRE materials). The results obtained are in agreement with current knowledge in soil science that clayrich soils normally have very poor drainage characteristics, unlike most sandy soils, and that the content and type of clay are key influence factors. Here, it may be helpful to mention, for example, the experimental work of Forster et al. (2008) or that of Bui et al. (2014).

\section{Mechanisms}

The mechanisms by which stabilizers act depend, inter alia, on the amount in which they are used, as well as on the particle size of the earth material. Initially, stabilizers may create a matrix that improves the cohesion of the material or they may agglomerate the clay particles, thereby reducing their swelling potential. 


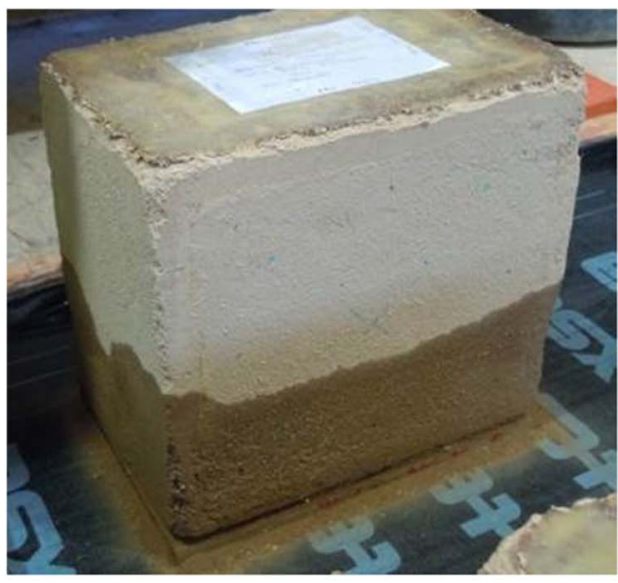

(a)

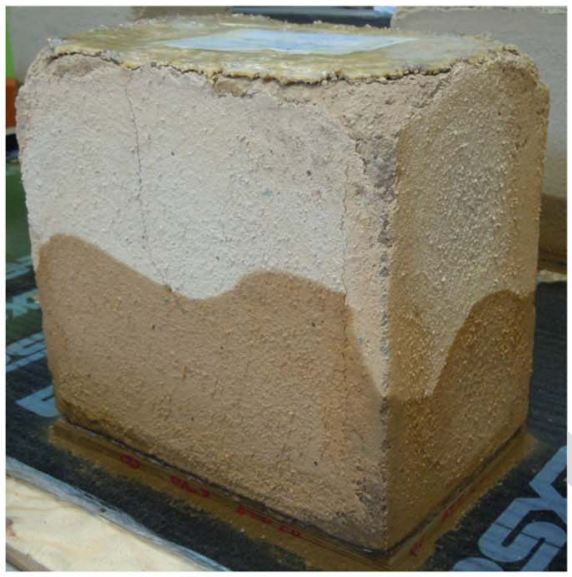

(b)

Fig. 15. Capillary absorption test performed on rammed earth blocks with Av material after $12 \mathrm{~h}$ : (a) unstabilized mortar with the same material of the block, MAv; (b) mortar with reference earth and natural hydraulic lime, MRE_HL

Granular soils (noncohesive) typically have particle size larger than cement grains and can, therefore, be coated with cement. In cohesive soils, many particles are finer than cement grains and thus cannot be coated with cement. As a result, a three-phase reaction with the clay occurs (Hall and Allinson 2009):

1. Hydration reactions form cement gels on the surface of clay aggregations, and the hydrated lime (Calcium Hydroxide) that is freed during hydration reacts with the clay;

2. Clay agglomerations are disaggregated by hydration products and are penetrated by the resultant cement gels; and

3. Cement gels and the clay aggregates become intimately bonded; this results in both an inert sand-cement matrix and a matrix of stabilized clay in the new structure.

The same researchers (Hall and Allinson 2010), a year later, reiterated that the addition of a chemical binding agent creates a high modulus matrix that both improves the cohesion and limits the extent to which particle friction/interlock is affected by pore water. The binder hydrates from a paste to form a gel structure comprising crystalline sheets of the clay. The calcium hydroxide from the lime, or formed during cement hydration, may also react slowly with clay and form calcium silicates and aluminates.

Al-Rawas et al. (2005) further refer that the behavior of cement is similar to that of lime. When lime is added to a clayish earth, it has an immediate effect on the properties of the earth, and reactions begin to occur as cation exchange begins to take place between the metallic ions associated with the surfaces of the clay particles and the calcium ions of the lime. Clay particles are surrounded by a diffuse hydrous double layer, which is modified by the ion exchange of calcium. This alters the density of the electrical charge around the clay particles, which leads to them being attracted closer to each other to form flocs, the process being termed flocculation (Bell 1996).

Nevertheless, Fernandes et al. (2007) state that "clay particles interfere with the bond between the sand particles and cement past matrix." The same source cites Herzog and Mitchell, "a claycement mixture cannot be regarded as a simple mixture of hydrated cement matrix bonding together unaltered clay particles, but should be considered as a system in which both clay and hydrating cement combine through secondary reactions." Herzog and Mitchell propose a model of the resultant microstructure in which a matrix is composed by sand and unreacted clay surrounded by a skeleton of hydrated cement. They propose that some of the clay reacts with (or is captured on the surface of) the skeleton, thereby strengthening it. The remainder of the clay stays in the clay-sand matrix. However, they have not published any evidence supporting this theory, cited in Fernandes et al. (2007).

The researchers agree that stabilizers may agglomerate the clay particles, reducing their swelling potential. The unstabilized materials revealed deviations from the expected linear dependence of the absorption curve on $t^{1 / 2}$, as opposed to the stabilized materials. The use of stabilizers allows a perfect dependence $t^{1 / 2}$.

Hall and Allinson (2009) also mention that the cement microstructure and/or the cement-soil interactions influence sorption by causing increased porosity. Because the addition of cement appears to increase sorptivity (as a measure of the capacity of the medium to absorb or desorb liquid by capillarity), the reduction in capillary potential is most likely created through enlargement of the effective mean pore diameter. The sorptivity appears to exhibit a positive relationship with the void ratio, which suggests that the addition of cement has the effect of increasing the quantity of permeable pore space within the material. The researchers suggest that the horizontal level, anomalous nonlinear behavior, appears in the first minutes on unstabilized earth mortars because the clay can act with its own characteristics, i.e., the clay become expansive and swells by absorbing water and blocks the existing pores, inhibiting sorptivity and reducing the pore sizes, thereby increasing the quantity of capillary active pores. Therefore, it is accompanied by a progressive increase of the quantity of capillary pores in relation to that of the dry soil. This feature will also depend on the type of clay in the mixture because there are clays that are capable of absorbing more or less water.

Clay has a different behavior when it is mixed with a binder. There is a chemical reaction between these different components. The binder acts as blocker of the clay structure, inhibiting the characteristics of the clay. This results in a matrix where clay is bonded and absorbed by the binder, leading to a new structure. This new structure presents the behavior of the binder. It is further observed that an increase of binder also increases the absorption of water. This is caused by the increase in porosity derived from an increased proportion of binder. However, the use of stabilizers eliminates swelling, enabling a perfect $t^{1 / 2}$ dependence.

\section{Summary and Conclusions}

The four unstabilized earth mortars depicted nonlinear (exponential) $t^{1 / 2}$ dependence during the first minutes of capillary suction. This anomalous behavior was probably caused by clay swelling. Stabilization with any of the four tested binders enabled 
linear $t^{1 / 2}$ dependence, even when only $5 \%$ was used, probably because the swelling did not take place in this case; this feature is inhibited. However, the stabilizers also significantly increased the capillary suction and the capillary porosity, in comparison with the unstabilized mortars, which suggests that the use of stabilizers may lead to an intensification of moisture-related anomalies in earth constructions.

It is conclusive that a higher percentage of stabilizers present a negative effect. This indicates that in practice, to repair unstabilized rammed earth walls, it will be more appropriate to use unstabilized mortars. This also has additional conservation benefits because it enables the repair of the structure on a like-to-like materials basis, the repair presenting enhanced durability.

Therefore, apart from contributing to the increase of embodied energy of the mortars, the use of binders as stabilizers in earth mortars for repair should be carefully equated, particularly when the construction elements may have contact with moisture.

\section{Acknowledgments}

M. I. Gomes was supported by a doctoral grant from the Fundação para a Ciência e a Tecnologia (FCT). Authors are grateful to the people who collaborated in the experimental work, in particular, LNEC technicians José Costa, João Junior, Luis Nunes, and Bento Sabala. The researchers thank George Hilbert for providing the natural cement within the ROCARE EU project. Thanks are also due to the companies Sorgila, Lusical, and Secil for providing the remaining materials.

\section{References}

Al-Rawas, A. A., Hago, A. W., and Al-Sarmi, H. (2005). "Effect of lime, cement, and Sarooj (artificial pozzolan) on the swelling potential of an expansive soil from Oman.” Build. Environ., 40(5), 681-687.

Arizzi, A., Viles, H., and Cultrone, G. (2012). "Experimental testing of the durability of lime-based mortars used for rendering historic buildings." Constr. Build. Mater., 28(1), 807-818.

Ashurst, J., and Ashurst, N. (1995). Practical building conservation: Brick, terracotta \& earth-English heritage technical handbook, Vol. 2, Hampshire, U.K.

Bell, F. G. (1996). "Lime stabilization of clay minerals and soils." Eng. Geol., 42(4), 223-237.

Bui, Q.-B., et al. (2014). "Effect of moisture content on the mechanical characteristics of rammed earth." Constr. Build. Mater., 54, 163-169.

CEN (European Committee for Standardization). (1999a). "Methods of test for mortar for masonry. Part 11: Determination of flexural and compressive strength of hardened mortar." EN 1015-11, Brussels, Belgium.

CEN (European Committee for Standardization). (1999b). "Methods of test for mortar for masonry. Part 3: Determination of consistence of fresh mortar (by flow table)." EN 1015-3, Brussels, Belgium.

CEN (European Committee for Standardization). (2005). "Methods of testing the cement. Part 1: Determination of mechanical strength." EN 196-1, Brussels, Belgium.

CEN (European Committee for Standardization). (2009). "Conservation of cultural property. Test methods: Determination of water absorption by capillarity." EN 15801, Brussels, Belgium.

CEN (European Committee for Standardization). (2011). "Cement. Part 1: Composition, specifications and conformity criteria for common cements." EN 197-1, Brussels, Belgium.

CEN (European Committee for Standardization). (2012). "Building lime. Part 1: Definitions, specifications and conformity criteria." EN 459-1, Brussels, Belgium.

Cid, J., Mazarrón, F. R., and Cañas, I. (2011). "Las normativas de construcción con tierra en el mundo.” Inf. de la Construcción, 63(523), 159-169 (in Spanish).
Fernandes, V. A., et al. (2007). "The effect of clay content in sands used for cementitious materials in developing countries." Cem. Concr. Res., 37(5), 751-758.

Forster, A. M., et al. (2008). "Traditional cob wall: Response to flooding." Struct. Surv., 26(4), 302-321.

Gomes, M. I., and Faria, P. (2011). "Repair mortars for rammed earth constructions." Proc., 12th Int. Conf. on Durability of Building Materials and Components, Michael Vasco Peixoto Freitas, Helena Corvacho, and Michael Lacasse, eds., Vol. 2, Faculdade de Engenharia da Universidade do Porto, Portugal, 689-696.

Gomes, M. I., Gonçalves, T. D., and Faria, P. (2012a). "Earth-based repair mortars: Experimental analysis with different binders and natural fibers." Proc., 1st Int. Conf. on Rammed Earth Conservation (RESTAPIA), C. Mileto, F. Vegas, and V. Cristini, eds., CRC Press/Balkema, Valencia, Spain, 661-668.

Gomes, M. I., Gonçalves, T. D., and Faria, P. (2012b). "Evaluación de la influencia del contenido de agua en la trabajabilidad del mortero de tierra." J. Cult. Heritage Stud., 25(2), 258-277.

Gomes, M. I., Gonçalves, T. D., and Faria, P. (2013). "The compatibility of earth-based repair mortars with rammed earth substrates." 3rd Historic Mortars Conf., Univ. of West Scotland, Glasgow, Scotland, 11-14.

Gomes, M. I., Gonçalves, T. D., and Faria, P. (2014). "Unstabilised rammed earth: characterization of the material collected from old constructions in south Portugal and comparison to normative requirements." Int. J. Archit. Heritage, 8(2), 185-212.

Gonçalves, T. D. (2007). "Salt crystallization in plastered or rendered walls." Ph.D. thesis, LNEC and IST, Technical Univ. of Lisbon, Lisbon, Portugal.

Hall, C., et al. (1995). "Water anomaly in capillary liquid absorption by cement-based materials." J. Mater. Sci. Lett., 14(17), 1178-1181.

Hall, M. R., and Allinson, D. (2009). "Influence of cementitious binder content on moisture transport in stabilised earth materials analysed using 1-dimensional sharp wet front theory." Build. Environ., 44(4), 688-693.

Hall, M. R., and Allinson, D. (2010). "Evaporative drying in stabilised compressed earth materials using unsaturated flow theory." Build. Environ., 45(3), 509-518.

Heathcote, K. A. (1995). "Durability of earthwall buildings." Constr. Build. Mater., 9(3), 185-189.

HighScore X'Pert [Computer software]. PANalytical, Almelo, Netherlands.

Hossain, K. M., and Mol, L. (2011). "Some engineering properties of stabilized clayey soils incorporating natural pozzolans and industrial wastes." Constr. Build. Mater., 25(8), 3495-3501.

Jaquin, P. A., Augarde, C. E., and Legrand, L. (2008). "Unsaturated characteristics of rammed earth." 1st European Conf. on Unsaturated Soils: Advances in Geo-Engineering, Taylor \& Francis Group, Durham, 417-422.

Jayasinghe, C., and Kamaladasa, N. (2007). "Compressive strength characteristics of cement stabilized rammed earth walls." Constr. Build. Mater., 21(11), 1971-1976.

Jiménez Delgado, M. C., and Guerrero, I. C. (2007). "The selection of soils for unstabilised earth building: A normative review." Constr. Build. Mater., 21(2), 237-251.

Keable, J. (1996). Rammed earth structure: A code of practice, Intermediate Technology, London.

Lockington, D. A., and Parlange, J. (2003). "Anomalous water absorption in porous." J. Phys. D. Appl. Phys., 36(6), 760-767.

New Mexico Code. (2006). "New México earthen building materials code 14.7.4." Construction Industries Division (CID), Regulation and Licensing Dept., Santa Fé, NM.

RILEM. (1980). "Recommended tests to measure the deterioration of stone and to assess the effectiveness of treatment methods. Test No. II.6 Water absorption coefficient (capillarity)." Mater. Struct. Res. Test., 13(75), 209.

ROCARE EU-Project. (2012). Manual on best practice in the application of roman cements, C. Gurtner, G. Hilbert, D. Hughes, R. Kozlowski, and J. Weber, eds, Wien, Austria.

SAZS (Standards Association Zimbabwe). (2001). "Standard code of practice for rammed earth structures." SAZS 724, Harare, ZImbabwe.

Washburn, E. W. (1921). "The dynamics of capillary flow." Phys. Rev., 17(3), 273-283. 